\title{
Identification of extended-spectrum-beta- lactamases(ESBLs), metallo-beta-lactamases (MBLs), Amp-C and KPC B-lactamases among Klebsiella pneumoniae isolated from adults and pediatric patients in Iran
}

\author{
Fatemeh Fallah ${ }^{1}$, Mojdeh Hakemi Vala ${ }^{2}$, Hossein Goudarzi ${ }^{2}$, Ali Hashemi ${ }^{2 \star}$, Arezou \\ Taherpour $^{3}$, Khadijeh Bigdeli Shamloo ${ }^{4}$, Fariba Haj Shirmohammadi ${ }^{4}$ and Maliheh Habibi ${ }^{2}$ \\ ${ }^{1}$ Pediatric Infections Research Center, Mofid Children Hospital, Shahid Beheshti University of Medical Sciences, \\ Tehran, Iran. \\ ${ }^{2}$ Department of Microbiology, Shahid Beheshti University of Medical Sciences, Tehran, Iran. \\ ${ }^{3}$ Department of Microbiology, Kurdistan University of Medical Sciences, Sanandaj, Iran. \\ ${ }^{4}$ Taleghani Hospital,Tehran, Iran.
}

Accepted 26 March, 2013

\begin{abstract}
Klebsiella pneumoniae is one of the major bacteria that cause acute infections. $\beta$-lactamases are main defensive mechanisms in bacteria against drugs. The aim of this study was to determine antibiotic resistance patterns and detection of extended-spectrum-beta-lactamase (ESBL), MBL, Amp-C and KPC $\beta$-lactamases among $K$. pneumoniae strains isolated from adults and infants. This descriptive study was done on $83 \mathrm{~K}$. pneumoniae isolated from two hospitals. Antibiotic susceptibility tests were performed by Kirby-Bauer disc diffusion and broth microdilution methods according to Clinical Laboratory Standards Institute (CLSI) guidelines. ESBLs, MBL, Amp-C and KPC producing strains were detected by phenotypic confirmatory test, combination disk diffusion test (CDDT), Amp-C detection kit and Modified Hodge test, respectively. From 83 K. pneumoniae strains, $48(57.5 \%), 3(3.5 \%), 23(28 \%)$ and $5(6 \%)$ were ESBL, MBL, Amp-C and KPC positive, respectively. In this study, Fosfomycin and Tigecycline were more active than other antibiotics. The results demonstrated that incidence of ESBLs, Amp-C, MBLs and KPC was critical especially in infants. Therefore, detection of drug resistance patterns in $K$. pneumoniae and $\beta$-lactamases producing isolates is important for the prevention and control of these infections.
\end{abstract}

Key words: Klebsiella pneumoniae, infants, extended-spectrum-beta-lactamase (ESBL), Amp-C, MBLs, KPC.

\section{INTRODUCTION}

Klebsiella pneumoniae is an opportunistic pathogen and a common cause of nosocomial infections such as pyogenic liver abscesses, meningitis, endophthalmitis, pneumonia, septicemias, urinary tract infections and soft tissue infections. Suitable options have been restricted for the treatment of infections with increase of multi-drug resistant (MDR) bacteria especially, K. pneumoniae nosocomial isolates (García-Sureda et al., 2011). It has been a very big problem treating infants infections due to MDR organisms (Roy et al., 2011). In some countries, many infant deaths occur as a result of MDR bacteria. Enzymes are major defensive mechanisms in some bac- 
teria against drugs (Drawz et al., 2010). The most clinically important enzymes are KPC-enzyme (Ambler class A), MBL enzymes (class B), Amp-C (class $C$ ) and ESBLs (class A), identified in K. pneumoniae as a source of nosocomial outbreaks in hospitals (Poirel et al., 2011; Thomson et al., 2010). ESBLs are currently reported as a major problem of drug resistance in K. pneumoniae (Ruiz de Alegría et al., 2011). ESBLs are enzymes that hydrolyze cephalosporins, penicillins and aztreonam and encoded by mobile elements such as plasmids. ESBL producing bacteria are usually resistant to drugs. Since ESBL genes are transmissible to other bacteria, it is necessary that ESBLs be tested for other bacteria in hospital and long-term care facility patient groups where ESBLs are encountered. Bacteria including both ESBL and AmpC enzymes are becoming more common (Thomson et al., 2010).

AmpC $\beta$-lactamases constitute a group of enzymes widely spread in Klebsiella pneumoniae. They inactivate cephalosporins such as ceftazidime, cefotaxime and cefpodoxime. Plasmid-mediated AmpC enzymes, which originated from chromosomal AmpC of variety organisms, have been reported since the 1980s (Mammeri et al., 2010). Carbapenem-hydrolyzing enzymes belonging to Ambler classes A, B, and D have been reported in the world among Klebsiella pneumoniae. Most of those bacteria are MDR. K. pneumoniae possessing the KPC $\beta$-lactamases is now spreading in some medical centers in USA and is being increasingly reported worldwide (Landman et al., 2009). KPC-producing isolates of $K$. pneumoniae and other bacteria have spread rapidly in the world especially in New York. Other reports have been described in other areas, including China, Greece, Demark, Argentina, Hungary, Brazil, Colombia, Finland, France, Italy, Germany, Sweden, Puerto Rico, Norway and the United Kingdom (Chen et al., 2011a). These strains typically possess an underlying ESBLs or Amp-C enzymes (Landman et al., 2009), which are a molecular class $A$ serine enzyme belonging to functional group $2 f$, that can hydrolyze carbapenems, penicillins, cephalosporins and aztreonam. These enzymes can be inhibited by clavulanic acid and tazobactam (Fontana et al., 2010). The metallo- $\beta$-lactamases, which have been reported in the 1960s, were detected in some countries. In the 1990 s, with the spread of enzymes encoding metallo- $\beta$ lactamases located on mobile elements such as plasmids, these $\beta$-lactamases increased in K. pneumoniae such as New Delhi metallo-beta-lactamase (NDM), Imipenemase (IMP), Australia imipenemase (AIM), Seoul imipenemase (SIM), Verona integron-encoded-metallo- $\beta$ lactamase (VIM), German imipenemase (GIM), Dutch imipenemase (DIM) and São Paolo metallo- $\beta$-lactamase (SPM) types (Cornaglia et al., 2011).

Recently, NDM-1 emerged as a global threat because the bacteria which possess this metallo- $\beta$-lactamase are resistant to almost all $\beta$-lactam antibiotics, aminoglycosides, fluoroquinolones and other classes of drug agents NDM-1 gene is located on plasmid or chromosome. The rapid emergence of NDM-1 has been related to transmissible plasmids which can transfer among dif-ferent isolates; subsequently, NDM-1 can spread throughout the world (Kus et al., 2011; Diene et al., 2011; Liang et al., 2011; Ong et al., 2011). So far, in Iranian studies on different bacteria, the emphasis has been on identification of Ambler class $A$ and class $D$ and also three reports on Ambler class B beta-lactamases (Fallah et al., 2011). The aim of this study was to determine antibiotic resistant patterns and detection of beta-lactamase types in K. pneumoniae isolated from hospitallized patients in Mofid Children and Taleghani hospitals, Tehran, Iran during 2012 year.

\section{MATERIALS AND METHODS}

\section{Bacterial isolates}

From October 2011 to May 2012, 83 non-duplicate and nonconsecutive Klebsiella pneumoniae that consisted of males 27 $(32.53 \%)$, females $14(16.86 \%)$ and infants $42(50.60 \%)$ were collected from hospitalized patients in Mofid Children and Taleghani hospitals, Tehran, Iran. The isolates were stored at $-20^{\circ} \mathrm{C}$ in trypticase soy broth containing $20 \%$ glycerol.

\section{Antimicrobial susceptibility testing}

Antimicrobial susceptibility of each Klebsiella pneumoniae isolates was determined by the Kirby-Bauer disk diffusion method (Mast Group, Merseyside, UK) on Mueller Hinton agar (Merck, Germany) and interpreted as recommended by Clinical Laboratory Standards Institute (CLSI, 2012) or FDA breakpoints (tigecycline) guidelines. Disks of Penicillins [Piperacillin (PIP, $100 \mu \mathrm{g}$ ), Ampicillin (AMP,10 $\mu \mathrm{g})$, Beta lactam/beta lactamase inhibitor combinations [Piperacillin/Tazobactam (PTZ, 100/10 $\mu \mathrm{g}$ )], Cephems [Ceftazidime (CAZ, $30 \mu \mathrm{g})$, Cefotaxime (CTX, $30 \mu \mathrm{g})$, Cefepime (FEP, $30 \mu \mathrm{g})$, Ceftriaxone (CRO, $30 \mu \mathrm{g})$, Cefpodoxime (CPD, $30 \mu \mathrm{g})$ ], Monobactams [Aztreonam (ATM, $30 \mu \mathrm{g})$ ], Carbapenems [Imipenem (IPM, $10 \mu \mathrm{g}$ ), Meropenem (MEM, $10 \mu \mathrm{g}$ ), Doripenem (DOR, $10 \mu \mathrm{g}$ ), Ertapenem (ETP, $10 \mu \mathrm{g})$ ], Aminoglicosides [Gentamicin (GEN,10 $\mu \mathrm{g})$, Amikacin (AK, $30 \mu \mathrm{g})$ ], Tetracyclines [Tetracycline $(\mathrm{TE}, 10 \mu \mathrm{g})$ ], Fluoroquinolones [Ciprofloxacin (CIP, $5 \mu \mathrm{g}$ )], inhibitors [Trimethoprim-sulfamethoxazole (TS, $2.5 \mu \mathrm{g})$ ], Fosfomycins [Fosfomycin/ Trometamol (FOT, $200 \mu \mathrm{g})$ ], Tigecycline (TGC, $15 \mu \mathrm{g}$ ) and were used and Escherichia coli ATCC25922 was used as a control strain.

\section{Minimum inhibitory concentration (MIC)}

Antimicrobial drug susceptibilities were determined according to the guidelines of the CLSI by broth microdilution. Muller-Hinton broth (Merck, Germany) with distinct dose of imipenem, meropenem, Cefepime, Ampicillin, Piperacillin/Tazobactam, Cefotaxime, Ceftriaxone and Ceftazidime (GLAXO England $\mathrm{Co}_{0}$ and Himedia) was prepared. After shaking, $0.1 \mathrm{ml}$ of diluted drug was added to each well of 96-well microtiter plates. Microbial suspensions were adjusted to 0.5 MacFarland and diluted in 1:10 with broth to yield $10^{7} \mathrm{CFU} / \mathrm{ml}$ and to each well, $0.005 \mathrm{ml}$ of the bacterial inoculums was seeded. Control line with no bacterial inoculation and Escherichia coli ATCC25922 was simultaneously maintained. Microplates were incubated at $37^{\circ} \mathrm{C}$ for 18 to $24 \mathrm{~h}$. The lowest concentration of the drugs that produced no visible bacterial growth 
was reported as the MIC.

\section{Phenotypic detection of MBL}

Combination disk diffusion test (CDDT) was performed for identification of MBLs by imipenem, meropenem, doripenem and ertapenem (Mast Group, Merseyside, UK) alone and in combination with EDTA.

The inhibition zones of the Imipenem and Imipenem + EDTA, Meropenem and Meropenem + EDTA, Doripenem + EDTA, Ertapenem and Ertapenem + EDTA discs were compared after $18 \mathrm{~h}$ of incubation in air at $37^{\circ} \mathrm{C}$. A zone diameter difference between the discs and discs + EDTA $\geq 7 \mathrm{~mm}$ was interpreted as a positive result for MBL production (Galani et al., 2008).

\section{Phenotypic detection of ESBL}

Detection of ESBLs was tested for all the isolates by Combination Disk Diffusion Test (CDDT) containing Ceftazidime (CAZ) and Cefotaxime (CTX) with CAZ $30 \mu \mathrm{g}+\mathrm{CA} 10 \mu \mathrm{g}$ and CTX $30 \mu \mathrm{g}+\mathrm{CA}$ $10 \mu \mathrm{g}$ per disc (Mast Group, Merseyside, UK). The zone of inhibitions was compared for the CTX, CAZ discs with that of the CAZ $30 \mu \mathrm{g}+$ clavulanic (CA) $10 \mu \mathrm{g}$ and CTX $30 \mu \mathrm{g}+$ CA 10 disc. An increase in zone diameter of $\geq 5 \mathrm{~mm}$ in the presence of clavulanic acid indicated the presence of ESBL in the test organism. E. coli ATCC 25922 and K. pneumoniae ATCC700603 were used as negative and positive controls for ESBL production, respectively.

\section{Phenotypic detection of KPC}

Identification of KPC enzyme was performed for all the $K$. pneumoniae by Modified Hodge Test. 0.5 McFarland dilution containing E. coli ATCC 25922 was prepared in $5 \mathrm{ml}$ of broth and then diluted in $1: 10$ by adding $0.5 \mathrm{ml}$ of the $0.5 \mathrm{McF}$ arland to $4.5 \mathrm{ml}$ of Mueller Hinton broth (Merck, Germany). A lawn of the 1:10 dilution of E. coli ATCC 25922 was streaked to a Mueller Hinton agar (Merck, Germany) plate and allow to dry for 4 to $5 \mathrm{~min}$. $10 \mu \mathrm{g}$ Ertapenem susceptibility disc (Mast Group, Merseyside, UK) was placed in the center of the test area.

In a line, test bacteria were streaked from the edge of the disc to the edge of the plate; and incubated for 18 to $24 \mathrm{~h}$ at $37^{\circ} \mathrm{C}$. After 18 to $24 \mathrm{~h}$ of incubation, they were examined for a clover leaf-type indentation at the intersection of the test bacteria and $E$. coli ATCC25922, within the zone of inhibition of the Ertapenem susceptibility disc.

\section{Phenotypic detection of Amp-C}

The detection kit for Amp-C was developed by mast group containing 3 discs-labeled A, B and C. 1: Disc A contains Cefpodoxime and an Amp-C enzyme inducer. 2: Disc B contains Cefpodoxime, an Amp-C enzyme inducer and an ESBL enzyme inhibitor. 3: Disc C contains Cefpodoxime, an Amp-C enzyme inducer, an ESBL enzyme inhibitor, and an Amp-C enzyme inhibitors. ESBL enzyme inhibitor is included the disc set (discs B and $C$ ) for identification of the existence of Amp-C enzyme when the bacteria are also co-producing ESBL enzyme. Bacteria were tested employing on plates of Mueller Hinton agar (Merck, Germany).

The discs were located on the inoculated agar surface and incubated at $37^{\circ} \mathrm{C}$ for 18 to $24 \mathrm{~h}$, and after incubation the zones of inhibition were measured; zones with a $\geq 5 \mathrm{~mm}$ increase in diameter around disc $\mathrm{C}$ compared with both discs $\mathrm{A}$ and $\mathrm{B}$ were considered positive for Amp-C existence (Halstead et al., 2012).

\section{Statistical analysis}

Our study is descriptive and experimental; therefore to analyze the results, we used MINITAB16 software. P.value and confidence intervals are $<0.05$ and $95 \%$, respectively.

\section{RESULTS}

\section{Clinical data, susceptibility testing, and screening for ESBL, MBL, Amp-C and KPC producers}

The isolates were $45(54.21 \%)$ of Taleghani and 38 $(45.79 \%)$ of Mofid Children hospitals and belonged to males $27(32.53 \%)$, females $14(16.86 \%)$ and infants 42 $(50.60 \%)$. The number of $K$. pneumoniae strains isolated from patients was 83 followed by $20(24.09 \%), 7$ (8.43\%), $4(4.81 \%), 0$ (0.0\%), 4 (4.81\%), $4(4.81 \%)$ and 44 $(53.01 \%)$ in the age group $>60$ years, 50 to 59 years, 40 to 49 years, 30 to 39 years, 20 to 29 years, 8 to 19 years and 0 to 7 years, respectively. The source of studied isolates was as follows: Pediatric unit, 38 (45.7\%); outpatient, 13 (15.6\%); intensive care units (ICUs), 9 (10.8\%); surgery, 7 (8.4\%); NICU, 4 (4.8\%); bone marrow transplant unit, 3(3.6\%); hematology, 2(2.4\%); endocrine, $2(2.4 \%)$; digestion, $2(2.4 \%)$; orthopedic $1(1.2 \%)$ and others, $2(2.4 \%)$.

Bacterial isolates were recovered from different clinical specimens: urine, 33 (39.7\%); blood culture, 27(32.5\%); wound, $7(8.4 \%)$; sputum, 7 (8.4\%); Intra-abdominal, 4 (4.8\%); cerebrospinal fluid, $1(1.2 \%)$ and other samples, 4 $(4.8 \%)$. Table 1 summarizes the clinical data of 48 isolates of ESBL-producing $K$. pneumoniae collected from Mofid Children and Taleghani Hospitals, Tehran, Iran. Antimicrobial drug-resistance patterns of $83 \mathrm{~K}$. pneumoniae isolates were ATM (49\%), MEM (20\%), GEN (29\%), CIP (46\%), AK (12\%), CAZ (46.7\%), IMI (20\%), CTX (50\%), FEP (36.15\%), TE (33\%), AMP (65\%), PIP (50\%), CRO (49\%), CPD (57\%), TGC (5\%), DOR $(20 \%)$, ETP $(21 \%)$, PTZ (22\%), TS (50\%) and FOT (3\%) (Table 2) and MIC isolates are shown in Table 3. The Combination Disk Diffusion Test (CDDT) was applied for detection ESBLs in 83 Klebsiella pneumoniae isolates using Ceftazidime and Cefotaxime alone and in combination with clavulanic acid that $48(57.5 \%)$ isolates were positive for production of ESBL that $28(62.3 \%)$ belonged to Taleghani Hospital and $20(52.7 \%)$ to Mofid Children hospital (Figure 1). Combination disk diffusion test showed that $3(3.5 \%)$ of 83 isolates of $K$. pneumoniae collected from Mofid Children and Taleghani Hospitals were MBL positive (Figure 2).

Amp-C screening by Mast Group kit showed that 23 $(28 \%)$ of isolates were Amp-C positive that belonged to Taleghani Hospital $14(31.3 \%)$ and $9(23.7 \%)$ to Mofid Children Hospital (Figure 3). Modified Hodge Test (MHT) was applied to detect KPC in $83 \mathrm{~K}$. pneumoniae that $5(6 \%)$ of isolates were KPC positive (KPC-positive isolates were $3(6.7 \%)$ of Taleghani Hospital and 2(5.3\%) 
Table 1. Distribution of ESBL, MBL, Amp-C and KPC-producing K. pneumoniae

\begin{tabular}{|c|c|c|c|c|c|c|c|c|c|c|}
\hline $\begin{array}{l}\text { Strain } \\
\text { ID }\end{array}$ & Hospital & Age & Sex & Sample & $\begin{array}{l}\text { Date of } \\
\text { isolation }\end{array}$ & Ward & ESBL & MBL & AmpC & KPC \\
\hline $\mathrm{K} 1$ & A & 80 & $\mathrm{M}$ & Sputum & 12.10 .2011 & ICU & + & - & + & + \\
\hline K2 & A & 53 & $\mathrm{~F}$ & Urine & 11.10 .2011 & Surgical & + & - & + & - \\
\hline K4 & $A$ & 79 & $M$ & Sputum & 23.10 .2011 & ICU & + & - & + & - \\
\hline K5 & $A$ & 63 & $M$ & Sputum & 01.11 .2011 & Orthopedic & + & - & + & - \\
\hline K7 & A & Newborn & $\mathrm{F}$ & Unknown & 07.11 .2011 & $\mathrm{NICU}$ & + & - & + & - \\
\hline K9 & A & 43 & $\mathrm{M}$ & Wound & 07.11 .2011 & Surgical & + & - & + & - \\
\hline K12 & A & 52 & M & Blood & 07.11 .2011 & ICU & + & - & + & - \\
\hline K13 & A & 83 & $\mathrm{M}$ & Wound & 10.11 .2011 & ICU & + & - & + & + \\
\hline K16 & $A$ & Newborn & $\mathrm{F}$ & Blood & 01.12 .2011 & NICU & + & - & - & - \\
\hline K17 & $A$ & 49 & $M$ & Urine & 05.12 .2011 & Digestion & + & - & + & - \\
\hline K20 & $A$ & 60 & M & Intra-abdominal & 28.01.2012 & Digestion & + & - & - & - \\
\hline K21 & $A$ & 61 & $\mathrm{~F}$ & Blood & 02.02 .2012 & Hematology & + & - & - & - \\
\hline K22 & $A$ & Newborn & $M$ & Sputum & 04.02 .2012 & $\mathrm{NICU}$ & + & - & - & - \\
\hline K23 & $A$ & 48 & $\mathrm{~F}$ & Sputum & 09.02 .2012 & ICU & + & - & + & - \\
\hline K24 & $A$ & 73 & $\mathrm{~F}$ & Urine & 11.02 .2012 & Surgical & + & - & - & - \\
\hline K27 & $A$ & 75 & $\mathrm{~F}$ & Urine & 12.02 .2012 & Outpatient & + & - & - & - \\
\hline K30 & $A$ & 60 & $M$ & Intra-abdominal & 17.02.2012 & ICU & + & - & - & + \\
\hline K33 & $A$ & 80 & $M$ & Sputum & 19.02.2012 & ICU & + & - & - & - \\
\hline K34 & A & Newborn & $\mathrm{F}$ & Urine & 20.02.2012 & NICU & + & - & - & - \\
\hline K35 & A & 45 & $\mathrm{~F}$ & Blood & 21.02.2012 & Outpatient & + & + & + & - \\
\hline K36 & $A$ & 20 & $\mathrm{~F}$ & Sputum & 22.02.2012 & Bone marrow & + & - & - & - \\
\hline K38 & $A$ & Unknown & $\mathrm{F}$ & Unknown & 06.12 .2011 & Outpatient & + & - & - & - \\
\hline K40 & $A$ & 85 & M & Urine & 05.12 .2011 & Outpatient & + & + & + & - \\
\hline K41 & $A$ & 15 & M & Intra-abdominal & 05.12 .2011 & Outpatient & + & - & - & - \\
\hline K42 & $A$ & 58 & $\mathrm{~F}$ & Urine & 05.12 .2011 & Outpatient & + & - & - & - \\
\hline K43 & $A$ & 22 & $M$ & Wound & 12.02.2012 & Surgical & + & - & + & - \\
\hline K44 & $A$ & 66 & $F$ & Urine & 12.02.2012 & ICU & + & - & + & - \\
\hline K45 & $A$ & 68 & $\mathrm{~F}$ & Urine & 12.02.2012 & Outpatient & + & - & - & - \\
\hline K46 & $\mathrm{B}$ & Infant & $M$ & Urine & 02.05 .2011 & Pediatric & + & - & + & - \\
\hline K47 & B & Infant & $M$ & Blood & 03.05.2011 & Pediatric & + & - & + & - \\
\hline K49 & $B$ & Infant & $M$ & Urine & 06.05 .2011 & Pediatric & + & - & - & + \\
\hline K50 & $B$ & Infant & $F$ & Urine & 07.05 .2011 & Pediatric & + & - & - & - \\
\hline K51 & $B$ & Infant & $M$ & Blood & 09.05 .2011 & Pediatric & + & - & + & - \\
\hline K57 & $B$ & Infant & $F$ & Urine & 05.06 .2011 & Pediatric & + & - & - & - \\
\hline K58 & $B$ & Infant & $F$ & Urine & 13.06.2011 & Pediatric & + & - & + & - \\
\hline K60 & B & Infant & $M$ & Urine & 18.06 .2011 & Pediatric & + & - & - & - \\
\hline K64 & B & Infant & $F$ & Blood & 05.07.2011 & Pediatric & + & - & - & - \\
\hline K66 & $B$ & Infant & $M$ & Blood & 14.07.2011 & Pediatric & + & - & - & - \\
\hline K69 & B & Infant & $\mathrm{F}$ & Urine & 05.08 .2011 & Pediatric & + & + & + & - \\
\hline K70 & $B$ & Infant & $M$ & Urine & 09.08 .2011 & Pediatric & + & - & + & - \\
\hline K71 & $B$ & Infant & $\mathrm{F}$ & Urine & 12.08 .2011 & Pediatric & + & - & - & - \\
\hline K72 & B & Infant & $\mathrm{F}$ & Urine & 14.08 .2011 & Pediatric & + & - & + & + \\
\hline K75 & $B$ & Infant & $\mathrm{M}$ & Blood & 28.08.2011 & Pediatric & + & - & + & - \\
\hline K76 & $B$ & Infant & $\mathrm{M}$ & Blood & 06.09 .2011 & Pediatric & + & - & - & - \\
\hline K78 & $B$ & Infant & $M$ & Blood & 15.09 .2011 & Pediatric & + & - & + & - \\
\hline K79 & B & Infant & $\mathrm{M}$ & Urine & 16.09 .2011 & Pediatric & + & - & - & - \\
\hline K81 & B & Infant & $\mathrm{F}$ & Urine & 26.09.2011 & Pediatric & + & - & - & - \\
\hline K83 & $\mathrm{B}$ & Infant & $\mathrm{M}$ & Blood & 02.10 .2011 & Pediatric & + & - & - & - \\
\hline
\end{tabular}

A, Taleghani Hospital; B, Mofid Children Hospital; M, male; F, female; +, positive; - , negative. 
Table 2. Antimicrobial susceptibility testing results of 83 isolates of Klebsiella pneumoniae collected from Mofid Children and Taleghani Hospitals, Tehran, Iran.

\begin{tabular}{lccc}
\hline Antibiotic & $\begin{array}{c}\text { Resistant } \\
\text { no. }(\%)\end{array}$ & $\begin{array}{c}\text { Intermediate } \\
\text { no. }(\%)\end{array}$ & $\begin{array}{c}\text { Sensitive } \\
\text { no. (\%) }\end{array}$ \\
\hline Aztreonam $(10 \mu \mathrm{g})$ & $49(59)$ & $3(3.6)$ & $31(37.3)$ \\
Meropenem $(10 \mu \mathrm{g})$ & $20(24)$ & $2(2.4)$ & $61(73.5)$ \\
Gentamicin $(10 \mu \mathrm{g})$ & $29(35)$ & $3(3.6)$ & $51(61.5)$ \\
Ciprofloxacin $(30 \mu \mathrm{g})$ & $46(55.5)$ & $4(4.8)$ & $33(39.7)$ \\
Amikacin $(30 \mu \mathrm{g})$ & $12(14.4)$ & $4(4.8)$ & $67(80.7)$ \\
Ceftazidime $(30 \mu \mathrm{g})$ & $46(55.4)$ & $3(3.6)$ & $34(41)$ \\
Imipenem $(10 \mu \mathrm{g})$ & $20(24)$ & $2(2.4)$ & $61(73.5)$ \\
cefotaxime $(30 \mu \mathrm{g})$ & $50(60.2)$ & $2(2.4)$ & $31(37.3)$ \\
Cefepime $(\mathrm{FEP}, 30 \mu \mathrm{g})$ & $30(36.15)$ & $9(10.8)$ & $44(53.05)$ \\
Tetracycline(TE,10 $\mu \mathrm{g})$ & $33(39.7)$ & $3(3.6)$ & $57(68.6)$ \\
Ampicillin $(\mathrm{AMP}, 10 \mu \mathrm{g})$ & $65(78.3)$ & $2(2.4)$ & $16(19.2)$ \\
Piperacillin $(\mathrm{PIP}, 100 \mu \mathrm{g})$ & $50(60.2)$ & $0(0.0)$ & $33(39.7)$ \\
Ceftriaxone $(\mathrm{CRO}, 30 \mu \mathrm{g})$ & $49(59)$ & $2(2.4)$ & $32(38.5)$ \\
Cefpodoxime $(\mathrm{CPD}, 30 \mu \mathrm{g})$ & $57(68.6)$ & $3(3.6)$ & $23(27.7)$ \\
Tigecycline $(\mathrm{TGC}, 15 \mu \mathrm{g})$ & $5(6.02)$ & $25(30.1)$ & $53(63.8)$ \\
Doripenem $(\mathrm{DOR}, 10 \mu \mathrm{g})$ & $20(24)$ & $1(1.2)$ & $62(74.6)$ \\
Ertapenem $(\mathrm{ETP}, 10 \mu \mathrm{g})$ & $21(25.3)$ & $2(2.4)$ & $57(68.6)$ \\
Piperacillin/Tazobactam (PTZ,100/10 $\mu \mathrm{g})$ & $22(26.5)$ & $5(6.02)$ & $56(67.4)$ \\
Fosfomycin/Trometamol $(\mathrm{FOT}, 200 \mu \mathrm{g})$ & $3(3.6)$ & $12(14.4)$ & $68(82)$ \\
\hline
\end{tabular}

Table 3. Microbiological activities of various antimicrobial agents against 83 K. penumoniae isolates.

\begin{tabular}{lccc}
\hline \multirow{2}{*}{ Antibiotics } & \multicolumn{3}{c}{$\mathbf{M I C}(\boldsymbol{\mu g} / \mathbf{m l})$} \\
\cline { 2 - 4 } & Range & $\mathbf{5 0 \%}$ & $\mathbf{9 0 \%}$ \\
\hline Meropenem & $0.25-256$ & 1 & 32 \\
Imipenem & $0.25-256$ & 1 & 16 \\
Ceftazidime & $1->256$ & 64 & $>256$ \\
Ceftriaxone & $0.5->256$ & 16 & $>256$ \\
Cefepime & $0.5->256$ & 16 & $>256$ \\
cefotaxime & $0.5->256$ & 16 & $>256$ \\
Piperacillin/Tazobactam & $0.25-256$ & 4 & 128 \\
Ampicillin & $2->256$ & 256 & $>256$ \\
\hline
\end{tabular}

of Mofid Children Hospital (Figure 4). $\beta$-Lactamases content showed in $K$. pneumoniae alone or together (Table 4).

\section{DISCUSSION}

Effective use of microbiology laboratories is essential for controlling the spread of multi-drug resistant (MDR) pathogens and thereby decreasing the need to use drugs. Infection control is very beneficial to patients and also decreases mortality and morbidity rate in the world. The experiment in diagnostic microbiology is vital for detecting many resistant bacteria. Many bacteria may not be recognized because they have false resistance or susceptibility in conventional tests. This can lead to patients receiving unsuitable drugs and contribute to the spread of the bacteria to other patients. Therefore, the identification of such "Cryptic"resistance is so vital. Due to the fact that susceptibility assays may be unreliable, beneficial assays are required to detect the resistant mechanisms involved. These mechanisms are AmpC $\beta$ lactamases, extended-spectrum-beta-lactamases (ESBLs) and carbapenemases of molecular classes A and B especially KPC and NDM-1 (Thomson et al., 2010). This study exhibits that Fosfomycin and Tigecycline were more active than the other antibiotics. Leone et al. (2012) study showed that of $136 \mathrm{~K}$. pneumoniae, $37.1 \%$ were MDR and ESBL producers and $K$. pneumoniae strains were resistant to fluoroquinolones, 


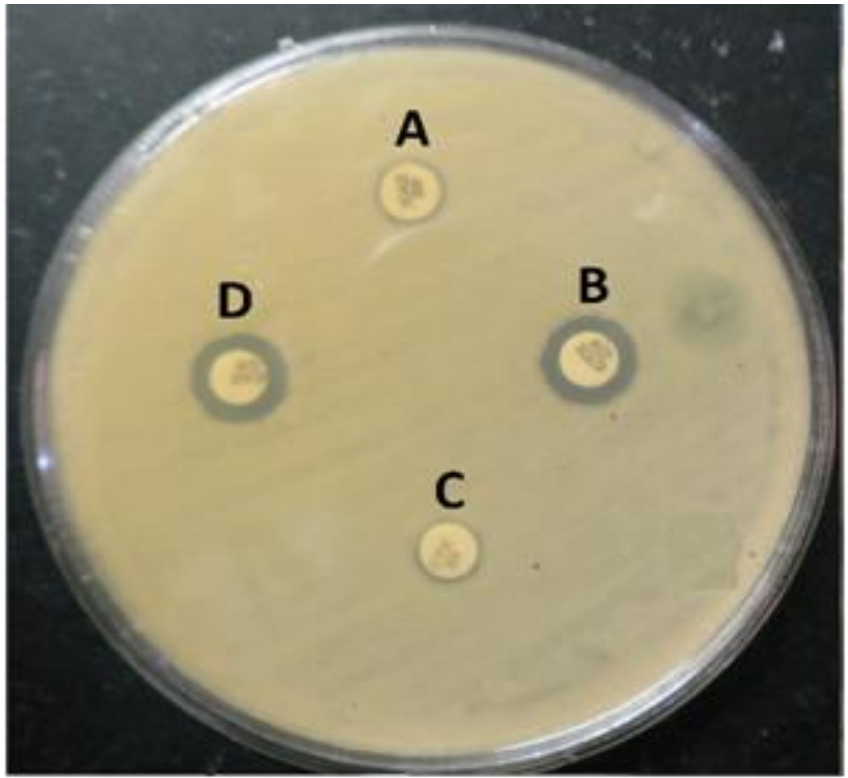

Figure 1. ESBL screening by CDDT showed that $48(57.5 \%)$ of isolates were ESBL positive. A CAZ disc, B CAZ 30 $\mu \mathrm{g}+\mathrm{CA} 10$ $\mu \mathrm{g}$ disc, C CTX disc and D CTX 30 $\mathrm{gg}+\mathrm{CA} 10 \mu \mathrm{g}$ disc.

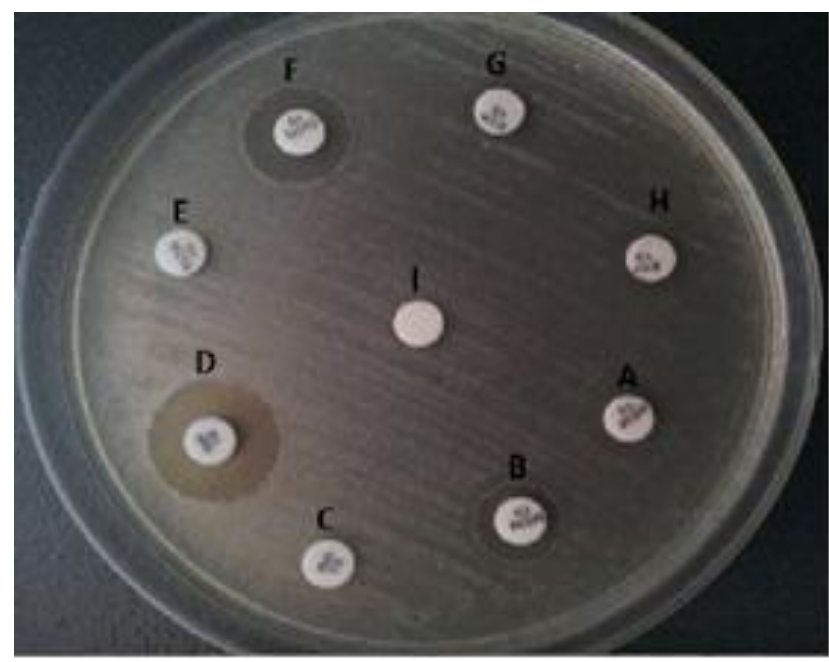

Figure 2. MBL screening by CDDT that $3(3.5 \%)$ of isolates were $\mathrm{MBL}$ positive. A MEM(10 $\mu \mathrm{g})$ disc, B $\operatorname{MEM}(10 \mu \mathrm{g})$ $+\operatorname{EDTA}(10 \mu \mathrm{L}), \mathrm{C}$ IMI $(10 \mu \mathrm{g})$ disc , D IMI $(10 \mu \mathrm{g})+\mathrm{EDTA}(10 \mu \mathrm{L})$

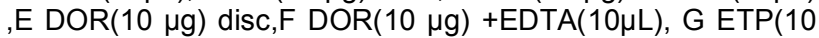
$\mu \mathrm{g}), \mathrm{H} \operatorname{ETP}(10 \mu \mathrm{g})+\operatorname{EDTA}(10 \mu \mathrm{L})$ disc and I EDTA disc.

gentamycin and $71 \%$ were resistant to imipenem. This study shows that $48(57.5 \%), 3(3.5 \%), 23(28 \%)$ and 5 (6\%) were ESBL, MBL, Amp-C and KPC positive, respectively. ESBL-producing $K$. pneumoniae were obtained from 24 adults and 33 pediatric patients in two hospitals.

This study confirms the relevant role of ESBL-KP as a pathogen in neonatal units. In the Taleghani Hospital, of 28 positive isolates, eight of ESBL-producing strains were

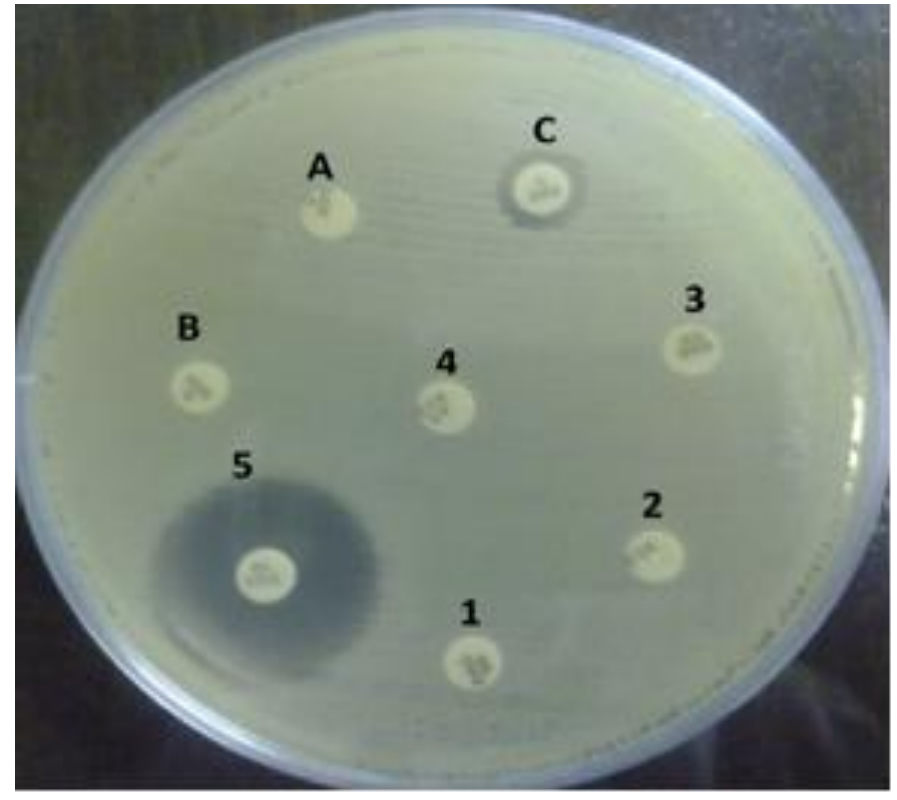

Figure 3. AmpC screening by Mast Group kit showed that $23(28 \%)$ of isolates were Amp-C enzyme positive.Disc A contains cefpodoxime and an Amp-C enzyme inducer. Disc B contains efpodoxime, an Amp-C enzyme inducer and an ESBL enzyme inhibitor. Disc C contains cefpodoxime, an Amp-C enzyme inducer, an ESBL inhibitor, and an Amp-C enzyme inhibitors. 1 CAZ disc, 2 CTX disc, 3 CAZ 30 $\mu \mathrm{g}+\mathrm{CA} 10 \mu \mathrm{g}$ disc, 4 CTX $30 \mu \mathrm{g}+\mathrm{CA} 10 \mu \mathrm{g}$ disc and $5 \mathrm{TGC}$ disc.

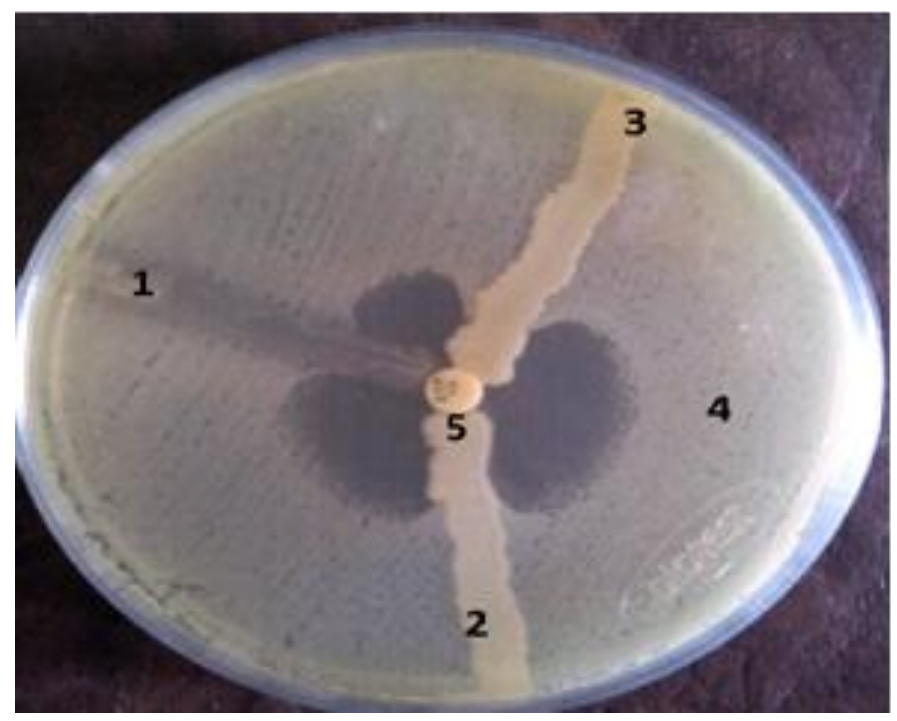

Figure 4. KPC screening by MHT that $5(6 \%)$ of isolates were KPC positive. (1) Positive control, (2) negative control, (3) clinical isolate, positive result, (4) E. coli ATCC 25922, (5) ETP disc.

related to ICU ward and four of ESBL-producing $K$. pneumoniae were detected in NICU ward and two isolates have simultaneously $\mathrm{ESBL}+\mathrm{Amp}-\mathrm{C}$ and $\mathrm{KPC}$ enzymes. 
Table 4. Number and percent $\beta$-lactamases present in Klebsiella pneumoniae collected from Mofid Children and Taleghani Hospitals, Tehran, Iran.

\begin{tabular}{lccc}
\hline $\boldsymbol{\beta}$-Lactamases content & $\begin{array}{c}\text { Taleghani } \\
\text { no. (\%) }\end{array}$ & $\begin{array}{c}\text { Mofid Childern } \\
\text { No. (\%) }\end{array}$ & Total no. (\%) \\
\hline ESBL & $28(62.3)$ & $20(52.7)$ & $48(57.5)$ \\
MBL & $2(4.4)$ & $1(2.6)$ & $3(3.5)$ \\
AmpC & $14(31.3)$ & $9(23.7)$ & $23(28)$ \\
KPC & $3(6.7)$ & $2(5.3)$ & $5(6)$ \\
ESBL + MBL & $2(4.4)$ & $1(2.6)$ & $3(4)$ \\
ESBL + AmpC & $11(24.4)$ & $12(31.6)$ & $23(28)$ \\
ESBL + KPC & $3(6.7)$ & $2(5.3)$ & $5(6)$ \\
ESBL + MBL + AmpC & $2(4.4)$ & $1(2.6)$ & $3(3.5)$ \\
ESBL + AmpC + KPC & $2(4.4)$ & $1(2.6)$ & $3(3.5)$ \\
ESBL + MBL + KPC & $0(0)$ & $0(0)$ & $0(0)$ \\
ESBL + MBL + KPC + AmpC & $0(0)$ & $0(0)$ & $0(0)$ \\
\hline
\end{tabular}

In a research in Spain, the results revealed that 133 adults and 29 pediatric patients were infected with ESBLproducing K. pneumoniae (Ruiz de Alegría et al., 2011). The wide use of drugs might facilitate the spread of antibiotic resistance, and thus control of beta-lactamases; especially, ESBL-producing $K$. pneumoniae within infant units should be considered as a precedence. Shigemoto et al showed that of 2,113 isolates of K. pneumoniae, 52 were ESBL-positive. Among the ESBL-positive $K$. pneumoniae, five isolates were also $\mathrm{MBL}$ positive (Shigemoto et al., 2012). In this study, 2 (4.4\%) of adults and $1(2.6 \%)$ of infants were MBL positive and 14 $(31.3 \%)$ of adults and $9(23.7 \%)$ of infants were Amp-C positive. The prevalence of Amp-C in Iran and the entire world is unknown, because laboratories have problem detecting this resistant mechanism accurately. Rodriguez-Bano et al showed that 100 patients were infected with plasmid-mediated Amp-C beta-lactamases including 17 Amp-C-producing $K$. pneumoniae (Rodríguez-Baño et al., 2012).

A study showed that $127(49.8 \%)$ of the test isolates (Proteus, E. coli and K. pneumoniae) were Amp-C positive (Tan et al., 2009). In this study, $3(6.7 \%)$ adults and $2(5.3 \%)$ infants were KPC positive. In a research in China, the results revealed that $70.6 \%(77 / 109)$ of $K$. pneumoniae were KPC positive and $59.6 \%(65 / 109)$ of isolates were $\mathrm{ESBL}+\mathrm{KPC}$ positive (Chen et al., 2011b). A study showed two patients with multidrug-resistant KPC-carbapenemase-producing K. pneumoniae urinary tract infections (Virgincar et al., 2011).

Our study is the first on infants that harbour types KPC and $\mathrm{MBL}$ as well as on $\mathrm{ESBL}+\mathrm{AmpC}+\mathrm{KPC}$ and $\mathrm{ESBL}$ $+\mathrm{MBL}+\mathrm{AmpC}$ in adults and children of Iran. Microbiology laboratories must be able to identify resistant bacteria in a timely manner, especially those that have false susceptibility in vitro to antibiotics that may be considered for therapy of infected adults and infants.

Bacteriological excellence is needed more than ever, and it is vital that ESBLs enzymes, AmpC and carbapenemases be promptly and accurately detected.

\section{ACKNOWLEDGEMENTS}

This work was financially supported by Pediatric Infectious Research Center in Mofid Children Hospital and Microbiology Department of Shahid Beheshti University of Medical Sciences, Tehran, Iran. The authors thank Dr. Mobayen (Islamic Azad University of Tabriz) and Dr. Pourakbari (Tehran University of Medical Sciences) for providing positive strains.

\section{REFERENCES}

Chen L, Mediavilla JR, Endimiani A, Rosenthal ME, Zhao Y, Bonomo RA, Kreiswirth BN (2011a). Multiplex real-time PCR assay for detection and classification of Klebsiella pneumoniae carbapenemase gene (bla KPC) variants. J. Clin. Microbiol. 49:579-585.

Chen S, Hu F, Xu X, Liu Y, Wu W, Zhu D, Wang H (2011b). High prevalence of KPC-2-type carbapenemase coupled with CTX-M-type extended-spectrum beta-lactamases in carbapenem-resistant Klebsiella pneumoniae in a teaching hospital in China. Antimicrob. Agents. Chemother. 55:2493-2494.

Cornaglia G, Giamarellou H, Rossolini GM (2011). Metallo-betalactamases: a last frontier for beta-lactams? Lancet. Infect. Dis. 11:381-393.

Diene SM, Bruder N, Raoult D, Rolain JM (2011). Real-time PCR assay allows detection of the New Delhi metallo-beta-lactamase (NDM-1)encoding gene in France. Int. J. Antimicrob. Agents. 37:544-546.

Drawz SM, Bonomo RA (2010). Three decades of beta-lactamase inhibitors. Clin. Microbiol. Rev. 23:160-201.

Fallah F,Taherpour A, Hakemi Vala M, Hashemi A (2011). Global spread of New Delhi metallo-beta-lactamase-1(NDM-1). Iran J Clin Infect Dis. 6(4): 171-177.

Fontana C, Favaro M, Sarmati L, Natoli S, Altieri A, Bossa MC, Minelli S, Leonardis F, Favalli C (2010). Emergence of KPC-producing Klebsiella pneumoniae in Italy. BMC Res Notes 3:40.

Galani I, Rekatsina PD, Hatzaki D, Plachouras D, Souli M, Giamarellou $\mathrm{H}$ (2008). Evaluation of different laboratory tests for the detection of metallo-beta-lactamase production in Enterobacteriaceae. J. Antimicrob. Chemother. 61:548-553.

Garcia-Sureda L, Juan C, Domenech-Sanchez A, Alberti S (2011). Role 
of Klebsiella pneumoniae LamB Porin in antimicrobial resistance. Antimicrob. Agents. Chemother. 55:1803-1805.

Halstead FD, Vanstone GL, Balakrishnan I (2012). An evaluation of the Mast D69C AmpC Detection Disc Set for the detection of inducible and derepressed AmpC beta-lactamases. J. Antimicrob. Chemother. 67:2303-2304.

Kus JV, Tadros M, Simor A, Low DE, McGeer AJ, Willey BM, Larocque C, Pike K, Edwards IA, Dedier H, Melano R, Boyd DA, Mulvey MR, Louie L, Okeahialam C, Bayley M, Whitehead C, Richardson D, Carr L, Jinnah F, Poutanen SM (2011). New Delhi metallo-betalactamase-1: local acquisition in Ontario, Canada, and challenges in detection. CMAJ 183:1257-1261.

Landman D, Bratu S, Quale J (2009). Contribution of OmpK36 to carbapenem susceptibility in KPC-producing Klebsiella pneumoniae. J. Med. Microbiol. 58:1303-1308.

Leone I, Mungo E, Bisignano G, Chirillo MG, Savoia D (2012). Klebsiella pneumoniae: emergence of multi-drug-resistant strains in Northwest Italy. J. Infect. 64:535-537.

Liang Z, Li L, Wang Y, Chen L, Kong X, Hong Y, Lan L, Zheng M, Guang-Yang C, Liu H, Shen X, Luo C, Li KK, Chen K, Jiang H (2011). Molecular basis of NDM-1, a new antibiotic resistance determinant. PLoS One 6:e23606.

Mammeri H, Guillon H, Eb F, Nordmann P (2010). Phenotypic and biochemical comparison of the carbapenem-hydrolyzing activities of five plasmid-borne AmpC beta-lactamases. Antimicrob. Agents. Chemother. 54:4556-4560.

Ong DC, Koh TH, Syahidah N, Krishnan P, Tan TY (2011). Rapid detection of the blaNDM-1 gene by real-time PCR. J. Antimicrob. Chemother. 66:1647-1649.

Poirel L, Revathi G, Bernabeu S, Nordmann P (2011). Detection of NDM-1-producing Klebsiella pneumoniae in Kenya. Antimicrob. Agents. Chemother. 55:934-936.
Rodriguez-Bano J, Miro E, Villar M, Coelho A, Gozalo M, Borrell N, Bou G, Conejo MC, Pomar V, Aracil B, Larrosa N, Aguero J, Oliver A, Fernandez A, Oteo J, Pascual A, Navarro F (2012). Colonisation and infection due to Enterobacteriaceae producing plasmid-mediated AmpC beta-lactamases. J. Infect. 64:176-183.

Roy S, Singh AK, Viswanathan R, Nandy RK, Basu S (2011). Transmission of imipenem resistance determinants during the course of an outbreak of NDM-1 Escherichia coli in a sick newborn care unit. J. Antimicrob. Chemother. 66:2773-2780.

Ruiz de Alegria C, Rodriguez-Bano J, Cano ME, Hernandez-Bello JR, Calvo J, Roman E, Diaz MA, Pascual A, Martinez-Martinez L (2011). Klebsiella pneumoniae strains producing extended-spectrum betalactamases in Spain: microbiological and clinical features. J. Clin. Microbiol. 49:1134-1136.

Shigemoto N, Kuwahara R, Kayama S, Shimizu W, Onodera M, Yokozaki M, Hisatsune J, Kato F, Ohge H, Sugai M (2012). Emergence in Japan of an imipenem-susceptible, meropenemresistant Klebsiella pneumoniae carrying blalMP-6. Diagn. Microbiol. Infect. Dis. 72:109-112.

Tan TY, Ng LS, He J, Koh TH, Hsu LY (2009). Evaluation of screening methods to detect plasmid-mediated AmpC in Escherichia coli, Klebsiella pneumoniae, and Proteus mirabilis. Antimicrob. Agents. Chemother. 53:146-149.

Thomson KS (2010). Extended-spectrum-beta-lactamase, AmpC, and Carbapenemase issues. J. Clin. Microbiol. 48:1019-1025.

Virgincar N, lyer S, Stacey A, Maharjan S, Pike R, Perry C, Wyeth J, Woodford $N$ (2011). Klebsiella pneumoniae producing KPC carbapenemase in a district general hospital in the UK. J. Hosp. Infect. 78:293-296. 